\title{
Seasonality in marine ecosystems: Peruvian seabirds, anchovy, and oceanographic conditions
}

\author{
Giannina Passuni, ${ }^{1,2,3,7}$ Christophe Barbraud, ${ }^{2}$ Alexis Chaigneau,,${ }^{3,4}$ Hervé Demarcq,,${ }^{1,3}$ Jesus Ledesma, ${ }^{3}$ \\ Arnaud Bertrand, ${ }^{1,3}$ Ramiro Castillo, ${ }^{3}$ Angel Perea, ${ }^{3}$ Julio Mori,${ }^{3}$ Vincent A. Viblanc,, 6 \\ Jose Torres-Maita, ${ }^{3}$ AND Sophie Bertrand ${ }^{1,3}$ \\ ${ }^{1}$ Institut de Recherche pour le Développement (IRD), UMR212 EME, Centre de Recherche Halieutique Méditerranéenne et \\ Tropicale, Avenue Jean Monnet, BP 171, 34203, Sète Cedex, France \\ ${ }^{2}$ UMR7372, CNRS, Centre d'Etudes Biologiques de Chizé, 79360, Villiers en Bois, France \\ ${ }^{3}$ IMARPE, Esquina Gamarra y General Valle S/N Chucuito, Callao, Lima, 07021, Peru \\ ${ }^{4}$ Laboratoire d'Etudes en Géophysique et Océanographie Spatiale, UMR CNRS, CNES, IRD, Université P. Sabatier, 14 Avenue \\ Edouard Belin, 31400, Toulouse, France \\ ${ }^{5}$ Département Ecologie, Physiologie, Ethologie, Institut Pluridisciplinaire Hubert Curien, Université de Strasbourg, 23 Rue \\ Becquerel, Strasbourg, 67087, France \\ ${ }^{6}$ UMR7178, CNRS, Strasbourg, 67087, France
}

\begin{abstract}
In fluctuating environments, matching breeding timing to periods of high resource availability is crucial for the fitness of many vertebrate species, and may have major consequences on population health. Yet, our understanding of the proximate environmental cues driving seasonal breeding is limited. This is particularly the case in marine ecosystems, where key environmental factors and prey abundance and availability are seldom quantified. The Northern Humboldt Current System (NHCS) is a highly productive, low-latitude ecosystem of moderate seasonality. In this ecosystem, three tropical seabird species (the Guanay Cormorant Phalacrocorax bougainvillii, the Peruvian Booby Sula variegata, and the Peruvian Pelican Pelecanus thagus) live in sympatry and prey almost exclusively on anchovy, Engraulis ringens. From January 2003 to December 2012, we monitored 31 breeding sites along the Peruvian coast to investigate the breeding cycle of these species. We tested for relationships between breeding timing, oceanographic conditions, and prey availability using occupancy models. We found that all three seabird species exhibited seasonal breeding patterns, with marked interspecific differences. Whereas breeding mainly started during the austral winter/early spring and ended in summer/early fall, this pattern was stronger in boobies and pelicans than in cormorants. Breeding onset mainly occurred when upwelling was intense but ecosystem productivity was below its annual maxima, and when anchovy were less available and in poor physiological condition. Conversely, the abundance and availability of anchovy improved during chick rearing and peaked around the time of fledging. These results suggest that breeding timing is adjusted so that fledging may occur under optimal environmental conditions, rather than being constrained by nutritional requirements during egg laying. Adjusting breeding time so that fledglings meet optimal conditions at independence is unique compared with other upwelling ecosystems and could be explained by the relatively high abundances of anchovy occurring throughout the year in the NHCS.
\end{abstract}

Key words: anchovy; Engraulis ringens; Guanay Cormorant; Northern Humboldt Current System; occupancy model; oceanographic variability; Pelecanus thagus; Peru; Peruvian Booby; Peruvian Pelican; Phalacrocorax bougainvillii; prey abundance; seasonal breeding; Sula variegata.

\section{INTRODUCTION}

For animals reproducing in fluctuating environments, breeding timing is often critical to success (Lack 1968, Cushing 1990). In birds and mammals, the intrinsic determinants of breeding timing (e.g., hormones [Prendergast 2005], energy status [Perrins 1970]) are suggested to evolve in response to bottom-up processes,

Manuscript received 13 June 2014; revised 2 June 2015; accepted 15 June 2015. Corresponding Editor: E. G. Cooch.

${ }^{7}$ E-mail: gianninapassuni@gmail.com such as spatial and temporal resource availability (Hamer et al. 2002).

Indeed, current theories propose that food availability often constrains the breeding season to a restricted period of the year when fitness benefits are maximal for both parents and their offspring. In birds, for instance, Lack (1968) suggested that seasonal variation in resource availability should select for the period of chick provisioning to match environmental peaks of food availability (optimal breeding time theory). Chick rearing is indeed regarded as one of the most 
energy-costly phases of the annual cycle (Drent and Daan 1980), and fitness returns may be greatest for genotypes that time reproduction in this way. In contrast, Perrins (1970) highlighted that female nutritional requirements early on in the breeding season may select breeding timing so that egg-laying matches periods of peak resource availability (egg-laying constraint theory).

For seabirds of temperate and polar marine ecosystems, seasonal breeding is primarily controlled by photoperiod (Wingfield and Kenagy 1991), and the precise date of egg laying appears to be driven by egg-laying constraints (Schroeder et al. 2009, Shultz et al. 2009). In contrast, in tropical ecosystems, seasonal changes in photoperiod are small and few studies have examined the correspondence between seasonal ecosystem productivity and seabird seasonal breeding from a bottom-up perspective (Le Corre 2001, Jaquemet et al. 2007).

One major drawback in explaining why nesting cycles are timed the way they are, or why breeding timing often shows such interannual variability, is the complexity of accurately documenting and measuring bottom-up processes (Hamer et al. 2002, Thompson et al. 2012). Indeed, one important challenge to overcome is the ability to simultaneously measure oceanographic processes, prey availability, and seabird responses on appropriate temporal (year-round) and spatial scales. Ideally, a relatively large number of contrasted seasons should be monitored for robust inferences to be drawn. At present, however, study durations are often too short to provide a comprehensive overview of the heterogeneity in ecosystem and trophic processes.

Here, over a period of $10 \mathrm{yr}$, we studied the relationships between seasonal breeding patterns, seasonal variation in physical oceanographic characteristics, and seasonal variation in prey abundance, prey availability, and prey quality for three tropical seabird species: the Guanay Cormorant (Phalacrocorax bougainvillii, Lesson 1837), the Peruvian Booby (Sula variegata, von Tschudi 1843), and the Peruvian Pelican (Pelecanus thagus, Molina 1872). Our study was carried out in the Northern Humboldt Current System (NHCS), the most equatorward region $\left(4-18^{\circ} \mathrm{S}\right)$ of the four major eastern boundary upwelling ecosystems worldwide (EBUE's: Benguela, Humboldt, California, and Canary). EBUEs are characterized by cool and nutrient-rich upwelling waters that strongly affect sea surface temperature and chlorophyll concentration in coastal waters (Chavez and Messié 2009, Sydeman et al. 2014). The upwelling of the low-latitude NHCS occurs year-round with moderate seasonality in oceanographic conditions, mainly modulated by the strength of winds (Echevin et al. 2008). This system also encompasses an intense and shallow oxygen minimum zone (OMZ; Fuenzalida et al. 2009), the upper limit of which (i.e., lower oxycline) is known to constrain the vertical distribution of prey fish species (Bertrand et al. 2010, 2011), affecting their availability to seabirds.
Our three study species are all endemic to the NHCS. They breed sympatrically in high numbers (global population $\sim 2-4$ million individuals; Peru National Institute for the Agricultural and Rural DevelopmentAGRORURAL, unpublished data) and compete for prey, especially Peruvian anchovy (Engraulis ringens), with a large-scale fishing industry off the coast of Peru (Jahncke et al. 2004). These seabirds are also the main contributors to guano production along the Peruvian coast (Duffy 1994). Yet, research on the seasonality of their breeding cycle is scarce, and existing studies are mostly restricted to a single season or few colonies (Jahncke and Paz-Soldan 1998), or were conducted before the development of industrial fishing (before the 1950s; Vogt 1942). The earliest work described those seabirds as year-round breeders, with incubation peaking in the late austral spring and early summer (November-December) when local anchovy abundance was high (Vogt 1942, Appendix S1: Fig. S1). Further, it was suggested that these seabirds might increase their breeding frequency and adjust their egglaying periods (Nelson 2005) in response to population decline (Jordan and Fuentes 1966) and severe El Niño Southern Oscillation events (Duffy 1990).

In this study, we merged data on seabird nesting seasons, oceanographic conditions, and prey availability to address three major questions: (1) Is the breeding cycle of cormorants, boobies, and pelicans in the NHCS characterized by marked seasonality? (2) Are there observable differences in the nesting cycles of the three species? (3) Do seasonal changes in oceanographic conditions and prey abundance, availability, and quality affect the breeding cycle of those seabirds? Documenting seasonal breeding patterns in relation to environmental characteristics and prey availability was expected to provide us with knowledge on the determinants of breeding cycles, in light of possible egg-laying constraints and/or optimal breeding windows in those tropical species.

\section{Materials And Methods}

\section{Study area and species}

Cormorants, boobies, and pelicans occur between $3^{\circ} \mathrm{S}$ and $42^{\circ} \mathrm{S}$ (Nelson 2005, Jeyasingham et al. 2013). Breeding sites are typically situated on arid and uninhabited islands and headlands, each breeding site hosting one to several colonies. Most islands are located within a $20-\mathrm{km}$ distance from the coast, except for Isla Lobos de Afuera $\left(7^{\circ} \mathrm{S}\right)$, which lies at some $60 \mathrm{~km}$ from the coast (Fig. 1). All species are considered to be annual breeders (Nelson 2005) and lay 1-4 eggs (cormorant, 2-4 eggs; booby, 1-4 eggs; pelican, 2-3 eggs). The length of the breeding period from egg laying to chick fledging is $\sim 4.7$ months for cormorants, $\sim 5.3$ months for pelicans, and $\sim 6.7$ months for boobies (Appendix S1). 


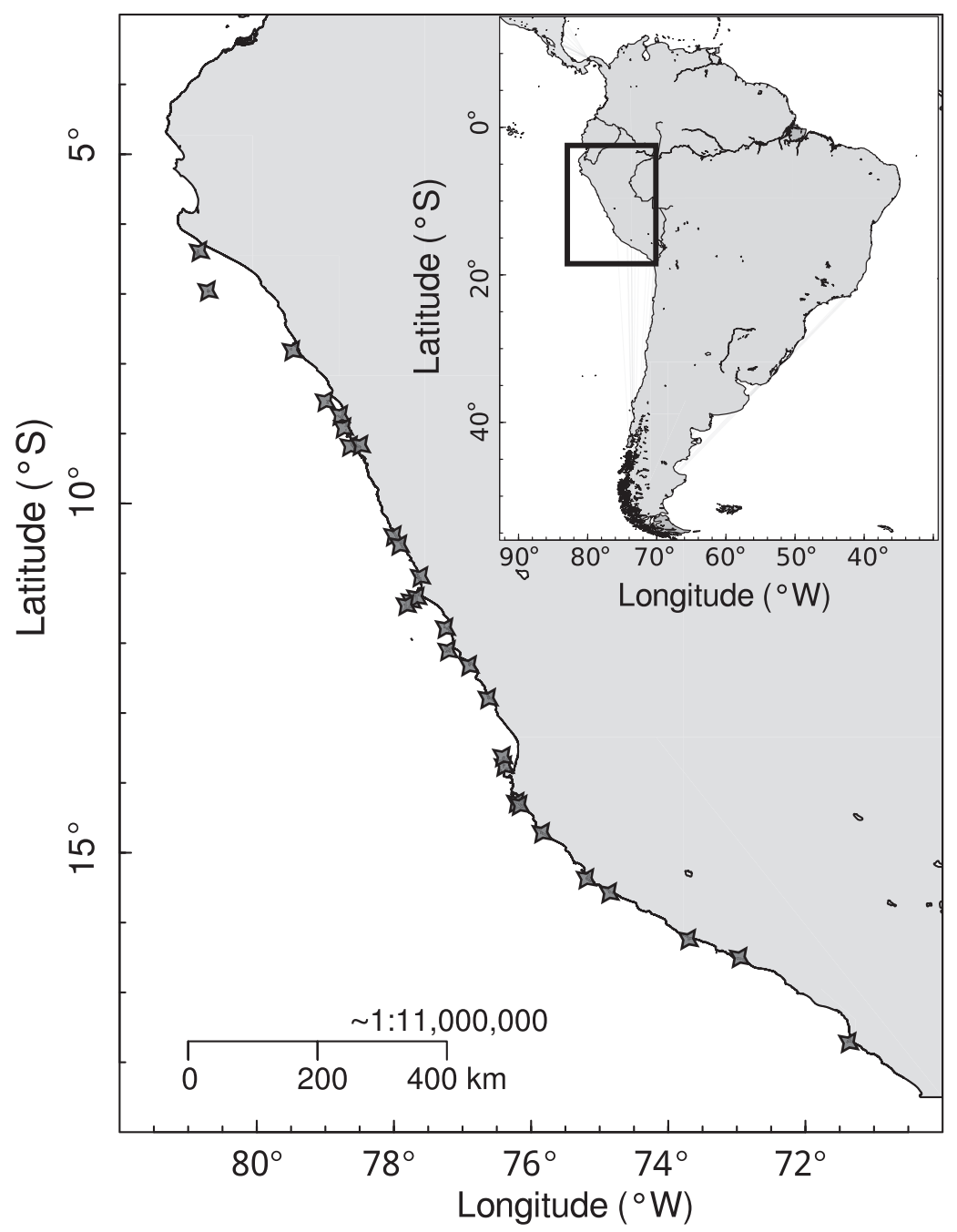

FIG. 1. Map figuring the 31 breeding sites of guano-producing seabirds (Guanay Cormorant Phalacrocorax bougainvillii, Peruvian Booby Sula variegata, and Peruvian Pelican Pelecanus thagus) monitored by AGRORURAL along the coast of Peru.

In the NHCS, AGRORURAL is the state institution responsible for guano harvesting in seabird colonies. AGRORURAL also ensures seabird conservation and protection through guardianship and monitoring of breeding sites. At the end of each month, one or two resident wardens from AGRORURAL perform a land-based census of the colonies for all three species at each breeding site. The wardens climb to the highest point of the island, mark observed patches of breeders (colonies) and non-breeders (flocks) on a standardized map of the site, and subsequently convert patch surfaces into an abundance index by applying a nest density factor that was pre-established for each species in the NHCS (see Appendices S3 and S4). Individuals are considered breeders if they are observed incubating eggs, brooding, or feeding chicks (Appendix S3). Colonies most often varied from thousands to tens of thousands of individual breeders (Appendix S4) and counts were strongly biased because (1) wardens varied in their experience, (2) some nesting areas, such as cliffs, were hard to monitor from the ground, and (3) whereas nest density varied across years and sites, the nest density conversion factor was assumed constant. Comparing concomitant ground and aerial surveys (used as a reference), revealed that ground counts underestimated colony size by $25-49 \%$ on average, depending on the species. Given this high uncertainty in abundance estimates and since our main interest was about the relationship between breeding seasonality and environmental conditions, we used information on the monthly presence and absence of birds at colonies as a primary dependent variable (see Appendix S4).

The monthly presence/absence of birds was thus determined at colonies of 31 sites (Fig. 1) from January 2003 to December 2012 (i.e., 120 months). Using multi-season site-occupancy models (MacKenzie et al. 2005), we investigated the seasonality of breeding 
patterns in relation to oceanographic and prey parameters (considered as covariates) and nesting habitat (considered as a nuisance variable). Nesting habitat features were fixed site-specific covariates that characterized the geographical situation of breeding sites.

Oceanographic covariates were both dynamic and site-specific, reflecting the spatiotemporal variations in oceanographic conditions surrounding each breeding site during the year. Prey covariates were also dynamic (but not site specific) and reflected the temporal variation encountered in prey abundance and condition in the NHCS throughout the year.

\section{Nesting habitat covariates}

Each breeding site was described with the following geographic features: (1) whether the breeding site was an island or a headland $(I / H)$, (2) its log-transformed distance from the coast (DC; in $\mathrm{km}$; null for headlands), and (3) its latitude (LAT).

\section{Oceanographic covariates}

Oceanographic covariates (Appendix S5) were remotely sensed by satellite and included chlorophyll $a$ concentrations $\left(\mathrm{Chlo} ; \mathrm{mg} / \mathrm{m}^{3}\right)$, sea surface temperatures (SST; $\left.{ }^{\circ} \mathrm{C}\right)$, and an upwelling index (UI) obtained from wind speed components. In addition, vertical profiles of dissolved oxygen concentrations acquired from research vessels of the Instituto del Mar del Peru (IMARPE) allowed us to determine dissolved oxygen concentrations (DO; mL/L) close to the surface $(0-5 \mathrm{~m})$ and the depth of the oxycline, defined as the depth where dissolved oxygen is equal to $2 \mathrm{~mL} / \mathrm{L}\left(Z_{2 \mathrm{~mL}} ; \mathrm{m}\right)$. Oxycline depth is a proxy of the upper limit of the oxygen minimum zone (Bertrand et al. 2010), and is associated with the limit of vertical anchovy distribution. Chlo, SST, UI, and DO reflected annual variations in ecosystem productivity. A climatology profile (monthly means over all years) for each covariate was computed within a $100 \mathrm{~km}$ radius around each colony using data from 2002-2012 for Chlo and SST, data from 1999-2009 for UI, and data from 1960-2010 for DO and $Z_{2 \mathrm{~mL}}$. This range encompassed the maximum recorded foraging ranges of the three species during breeding: $\sim 63 \mathrm{~km}$ for cormorants (S. Bertrand, unpublished data), $\sim 90 \mathrm{~km}$ for boobies, and $\sim 83 \mathrm{~km}$ for pelicans (Zavalaga et al. 2011, Bertrand et al. 2012).

\section{Prey covariates}

Acoustic data were collected two to four times a year during routine acoustic biomass estimation surveys performed along the Peruvian coast by IMARPE. In general, the survey design consisted of parallel crossshore transects $\sim 100$ nautical miles long (1 nautical mile $=1.852 \mathrm{~km})$, with $\sim 15$ nautical miles between transects (Gutiérrez et al. 2007, Simmonds et al. 2009, Appendix S6). Surveys were performed by research vessels equipped with 38 and $120 \mathrm{kHz}$ Simrad split beam scientific echosounders (EK500 and EK60; Simrad, Oslo, Norway) mounted on the hull. The echosounders were calibrated with a standard sphere (Foote et al. 1987). Nautical-area-backscattering coefficients $\left(s_{\mathrm{A}}\right.$ or NASC) were recorded in each georeferenced elementary distance sampling unit (ESDU; 1 nautical mile; Simmonds and Maclennan 2005). Here, we only considered the $s_{\mathrm{A}}$ attributed to anchovy by applying a $-65 \mathrm{~dB}$ (decibel) volume threshold on backscattering strengths, and by identifying echoes from associated catches during fishing trawls (Gutiérrez et al. 2007, Simmonds et al. 2009).

We analyzed the acoustic surveys from 1999-2011, a period with abundant anchovy and collapsed sardine stocks (Bertrand et al. 2011). For each survey, we subsampled the area between latitudes $6^{\circ} \mathrm{S}$ and $14^{\circ} \mathrm{S}$ to cover most of the breeding sites. The sampling ranged from the coast to $40 \mathrm{~km}$ offshore in order to cover both the core area of anchovy abundance (Bertrand et al. 2011) and the mean distance of foraging for cormorants and boobies (Weimerskirch et al. 2012). From this subsample we determined (1) regional anchovy abundance, i.e., the monthly mean $s_{\mathrm{A}}$ per ESDU; (2) local anchovy density, i.e., the monthly mean $s_{\mathrm{A}}$ per ESDU when anchovy were present $\left(s_{\mathrm{A}}^{+}\right)$; and (3) anchovy spatial distribution, i.e., the monthly spatial occupation index (ISO) computed as the percentage of ESDU where anchovy was present. For acoustic surveys conducted over 2 months, we calculated means based on the month with the most data. In a few cases, the numbers of days were similar for the 2 months, and the information was then split for each month (Appendix S6: Table S6). We built regional climatologies (monthly means over 1999-2011) for the three indices $\left(s_{\mathrm{A}}, s_{\mathrm{A}}^{+}\right.$, ISO). However the months of January, April, and May were not surveyed and only two surveys were performed in June and July (Appendix S5: Fig. S5).

To describe the physiological condition of anchovy we used (1) a body condition factor $\left(\mathrm{BCF} ; \mathrm{g} / \mathrm{cm}^{3}\right)$, defined as the ratio between eviscerated weight and the third power of the total length; and (2) a gonadosomatic index (GSI), defined as the proportion of gonad mass relative to total body mass. The detailed methodology for data collection and for calculating these physiological indices is described elsewhere (Buitrón et al. 2011; see Appendix S7). Climatologies (monthly means over all years) of the two indices (BCF, GSI) were computed from monthly reports of the north-central anchovy stock $\left(6-14^{\circ} \mathrm{S}\right)$ from 2002 2012 (Appendix S7: Fig. S7). We used the north-central stock because most seabird colonies were situated within this area. 


\section{Modeling seabird seasonal breeding and its relationship with oceanographic and prey covariates}

Multi-season occupancy models are dynamic models allowing making inferences (1) on the occurrence of events at a collection of sites, and (2) on how changes in occurrences are driven by colonization and local extinction (MacKenzie et al. 2005). We used the monthly presence and absence of breeders (Appendix S4: Table S4) in breeding sites (which contain one or several colonies) as a dynamic process of onset and termination of breeding events (colonization and local extinction). We estimated three parameters using multi-season occupancy models. First, we determined (1) the occupancy probability of a breeding site $(\psi)$ during the first month of the breeding season. Second, we determined changes in occupancy as (2) the onset probability $(\gamma)$ and (3) termination probability $(\varepsilon)$ of breeding events. The occupancy of a breeding site $(\psi)$ was defined as the probability of a breeding colony being present on the site. The onset probability of breeding events $(\gamma)$ was the probability that a breeding site without breeders in month $i$ was colonized in month $i+1$. The termination probability of breeding events $(\varepsilon)$ was the probability that a breeding site with breeders in month $i$ was deserted by breeders in month $i+1$. Models were fitted using maximum likelihood techniques using the PRESENCE software 6.1 (MacKenzie et al. 2005). Occupancy models were developed to produce unbiased estimates of occurrence when the probability of detecting a species was $p<1$, given its occurrence at a particular site (MacKenzie et al. 2005). In our case, however, given the absence of vegetation, the large size and conspicuousness of nesting colonies, and the permanent presence of wardens on the study sites, we considered that $p=1$.

We used a two-stage approach in model selection procedures. First, we compared a priori models to evaluate whether (1) the onset and termination of breeding obeyed a first order Markovian dynamic $(\gamma \neq \varepsilon)$ or not $(\gamma=\varepsilon)$; (2) the probabilities of breeding onset and termination varied monthly $([\gamma(\mathrm{m})$ $\varepsilon(m)], m=1: 12$ ), were full-time dependent over the 2003-2012 period $([\gamma(i) \varepsilon(i)], \quad i=1: 120)$, or were constant $([\gamma(.) \varepsilon()]$.$) ; and (3) the probabilities of onset$ and termination of breeding depended on nesting habitat covariates (I/H, LAT, DC). We modeled the influence of the geographical covariates on the onset and termination of breeding events using the logit function (Appendix S8). Models were ranked based on Akaike's information criterion (AIC). The lower the AIC, the better the fit of the model and two models with a difference in AIC $<2$ were assumed to be of similar predictive power (Burnham and Anderson 2002).

Second, based on the selected models, we modeled the influence of monthly variations in oceanographic and prey covariates on the onset and termination of breeding events using a logit function. We used the first axis of a principal component analysis (PCA) on the climatology of oceanographic variables instead of the original variables, to limit the number of covariates in the analyses and control for variable interdependence. For climatology of anchovy covariates, we did not perform a PCA and each covariate was modeled individually because data points were insufficient and unbalanced (seven points for acoustic data and 12 points for physiological covariates). In order to optimize convergence of the maximum-likelihood routine, covariates were standardized $\left(s_{\mathrm{A}}, s_{\mathrm{A}}^{+}, \mathrm{ISO}, \mathrm{BCF}\right.$, and GSI). We tested the effects of oceanographic and prey covariates on the onset and termination of breeding events using an analysis of deviance (ANODEV; Appendix S8), and quantified how much of the temporal variation in onset and termination of breeding events was accounted for by each covariate model using $R^{2}$ (Grosbois et al. 2008). We also tested the effects of oceanographic and prey covariates with time lags up to 3 months in order to test the hypothesis that changes in onset and termination of breeding events may be a response to earlier changes in environmental conditions.

\section{RESULTS}

\section{Seasonal onset and termination of breeding events}

The probabilities of breeding onset and termination were best represented by a first-order Markovian process (Appendix S9: Table S9). For all three species, models where breeding varied monthly had lower AIC than full-time and constant models (Appendix I: Table I2). For cormorants, breeding onset occurred almost throughout the year, initiating in April and reaching a maximum in October, before subsequently declining. The seasonality in breeding onset for boobies and pelicans was more pronounced than for cormorants (Fig. 2). In boobies and pelicans, breeding onset was rather restricted to a period between July and October, reaching a maximum in September for boobies (Fig. 2). Breeding termination probabilities were consistent with the duration of the main breeding stages from pre-laying attendance to the independence of fledglings (Appendix S9: Fig. S9). For the three species, these probabilities were particularly high from December to April, reaching a maximum in March for cormorants, in January for boobies, and in April for pelicans. Breeding termination probabilities declined after May, except for a peak in June for boobies and pelicans. In the rest of the study we only focus on breeding onset models, as the relationships between breeding termination, oceanographic, and prey covariates (see Appendix S9: Tables I4-I6) were inverse to those obtained for breeding onset. 

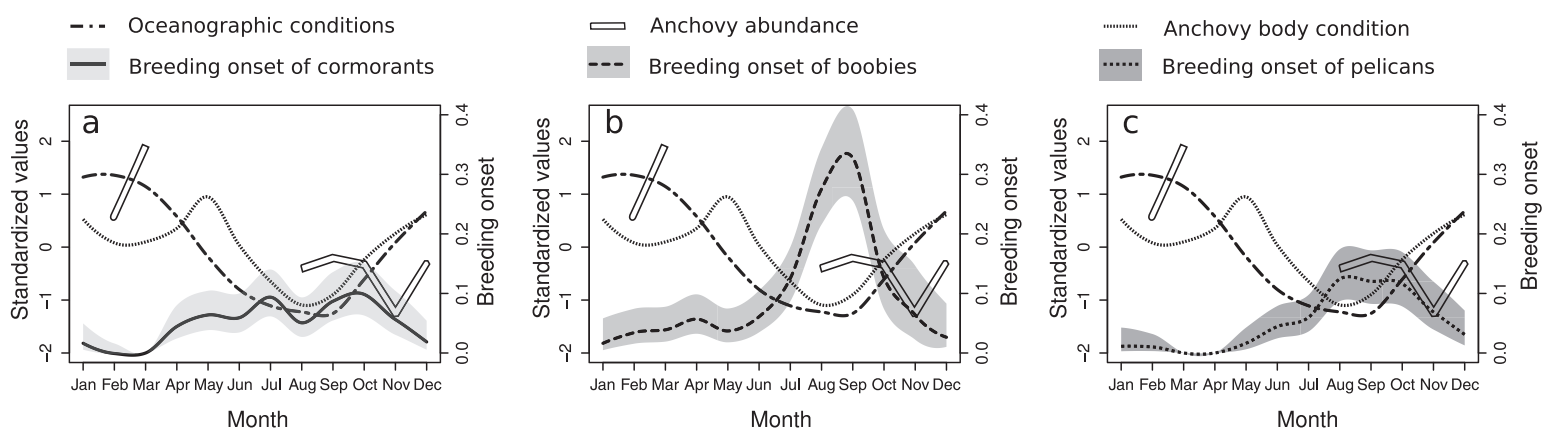

FIG. 2. Estimates of monthly probabilities of breeding onset for (a) cormorants (solid black line), (b) boobies (dashed line), and (c) pelicans (dotted thick line) related to oceanographic conditions ( $\mathrm{PC} 1$, dot-dashed lines), standardized anchovy abundance $\left(s_{\mathrm{A}}\right.$, outlined white lines), and standardized anchovy body condition (BCF, dotted thin lines). Shaded areas correspond to $95 \%$ confidence intervals. Lines of breeding onset, oceanographic conditions, and anchovy body conditions were smoothed with a loess model with 0.45 of span.
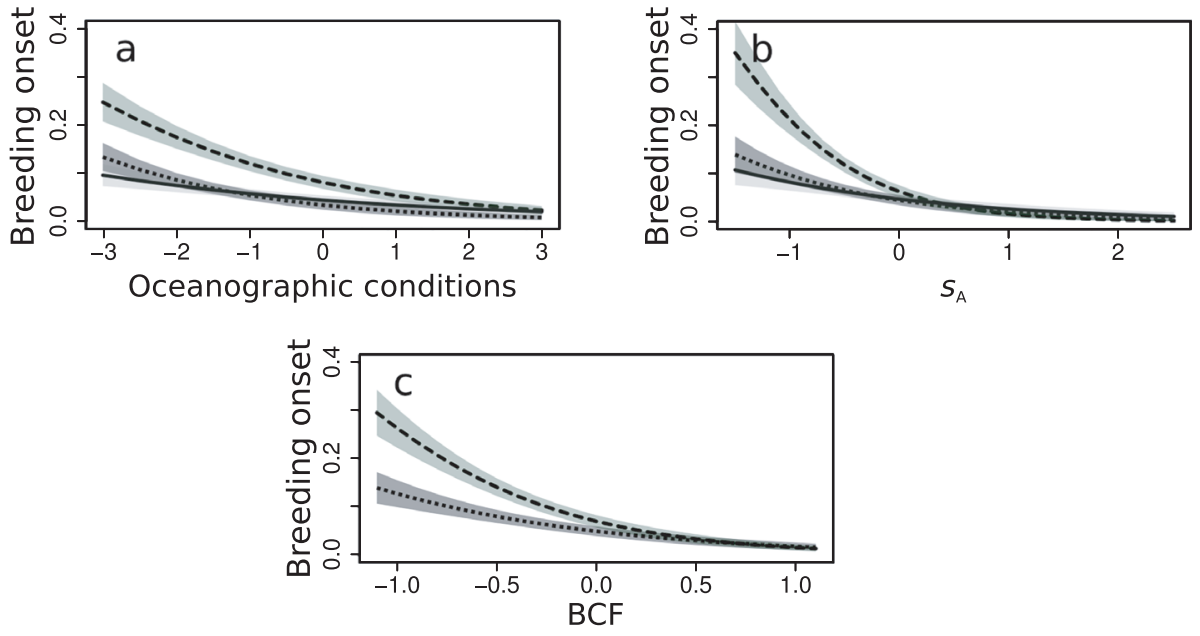

FIG. 3. Modeled probabilities of breeding onset as a function of (a) oceanographic conditions (PC1 standardized), (b) $s$ (anchovy abundance), and (c) BCF (anchovy body condition) for cormorants (solid lines), boobies (dashed lines), and pelicans (dotted lines). The functional relationships were obtained from the selected models for each species $\left(P<0.005\right.$ and highest $\left.R^{2}\right)$. Shaded areas represent $95 \%$ confidence intervals.

\section{Effects of nesting habitat covariates on breeding onset probability}

Site covariates influenced the magnitude of breeding onset probabilities (Appendix S9: Table I3) without changing the nesting cycle patterns described previously. For cormorants and boobies, breeding onset probabilities were higher on islands than on headlands. For pelicans, islands located farther away from the coast had higher breeding onset probabilities. For all three species, latitude had a lower effect on breeding onset probabilities than island/headland covariates.

\section{Effects of oceanographic conditions on breeding onset probability}

Oceanographic covariates exhibited moderate seasonal cycles (Appendix S5: Fig. S5). We differentiated two groups of oceanographic variables exhibiting contrasted monthly patterns. One group regrouped SST, Chlo, and DO with maximum values observed during austral summer (DO in January, SST in February, and Chlo in March-April) and minimum values in the austral winter (DO in July, SST in September, and Chlo in August). In contrast, the second group of covariates (UI and $Z_{2 \mathrm{~mL}}$ ) reached maximum values during the austral winter (September) and minimum values in summer (UI in January and $Z_{2 \mathrm{~mL}}$ in February; Appendix S5: Fig. S5). The seasonal variability of oceanographic covariates was synthesized with the first PCA axis (PC1), which represented 89.1\% of the total variance (only $7.3 \%$ on the second component; Appendix S5: Fig. S5.). The seasonality of oceanographic conditions (Chlo, SST, DO, UI, and $Z_{2 \mathrm{~mL}}$ ) was related primarily to upwelling and primary production (Fig. 2).

A higher UI associated with a deeper $Z_{2 \mathrm{~mL}}$, lower SST, lower Chlo, and lower DO (PC1 values $<0)$ 


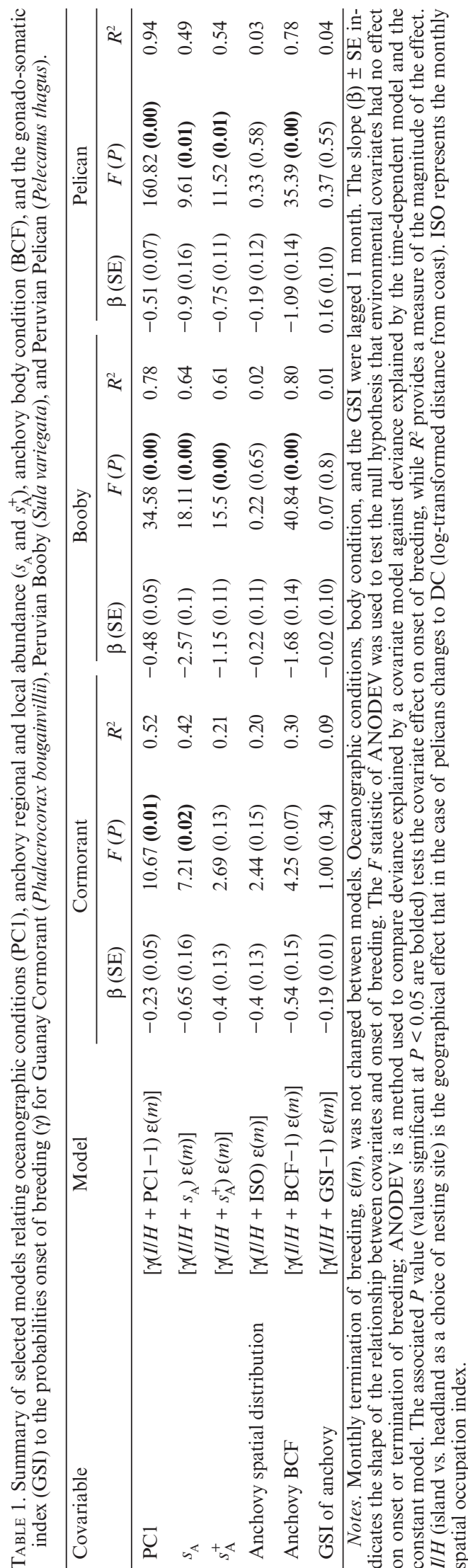

corresponded to higher breeding onset probabilities (Fig. 3). The relationships between onset probabilities and PC1 were consistent between species (Table 1). For all three species, all models including PC1 with time lags of up to 2 months indicated significant relationships with breeding onset ( $F$ tests: all significant at $P<0.05$; Appendix S9: Table I4). However, models with a 1-month lag performed generally better at explaining seasonal variation in breeding onset probabilities (Appendix S9: Table I4).

\section{Effects of prey availability and anchovy condition on breeding onset probabilities}

Although the observations of anchovy abundance were limited by a lack of acoustic data in January and April-July, regional and local anchovy abundance $\left(s_{\mathrm{A}}\right.$ and $s_{\mathrm{A}}^{+}$) exhibited moderate seasonality (Appendix F: Fig. F2). In contrast, no seasonality was observed in anchovy spatial distribution (ISO; Appendix S6: Fig. S6). Thus, anchovy abundance was higher in the austral summer than in spring (Fig. 2). Anchovy physiological condition also exhibited marked seasonality (Fig. 2). Maximum values of body condition (BCF) were found during the austral summer (December) and in autumn (May). In contrast minimum values were found during the austral winter (August). The gonadosomatic index (GSI) exhibited a marked seasonal cycle with a maximum centered on the austral spring (September-December) and a minimum during the austral autumn (May; Appendix S7: Fig. G1).

The regional abundance of anchovy $\left(s_{\mathrm{A}}\right)$ was negatively related with breeding onset for all three species, and the local abundance of anchovy $\left(s_{\mathrm{A}}^{+}\right)$was negatively related to breeding onset in boobies and pelicans ( $F$ tests: all $P<0.05$, Table 1; Appendix S9: Table I5). Thus, when $s_{\mathrm{A}}$ and $s_{\mathrm{A}}^{+}$increased, probabilities of breeding onset decreased (Fig. 3). Anchovy body condition (BCF) had negative effects on breeding onset for boobies and pelicans ( $F$ tests: all $P<0.05$, Table 1 ). Thus, when anchovies were in poorer physiological condition, breeding onset probabilities were higher (Fig. 3). The gonado-somatic index (GSI) had no significant effect on breeding onset for any of the three species. Covariate models of BCF with a zero and 1-month lag generally best explained the seasonal variation in breeding onset probabilities (highest $R^{2}$; Appendix S9: Table I6).

\section{DisCUSSION}

Our results provide insights into the possible drivers of seasonal breeding for cormorants, boobies, and pelicans in the NHCS. First, we highlighted marked differences in breeding onset between the three species. Whereas breeding onset varied seasonally for all species, cormorants had a protracted 


\begin{tabular}{|c|c|c|c|c|c|c|c|c|c|c|c|c|}
\hline & \multicolumn{2}{|c|}{ Fall } & \multicolumn{3}{|c|}{ Winter } & \multicolumn{3}{|c|}{ Spring } & \multicolumn{3}{|c|}{ Summer } & \multirow{2}{*}{$\begin{array}{c}\text { Fall } \\
\text { Apr }\end{array}$} \\
\hline & May & Jun & Jul & Aug & Sep & Oct & Nov & Dec & $\operatorname{Jan}$ & Feb & Mar & \\
\hline \multicolumn{13}{|l|}{ Cormorant breeding onset } \\
\hline \multicolumn{13}{|l|}{ Cormorant independence } \\
\hline \multicolumn{13}{|l|}{ Booby breeding onset } \\
\hline \multicolumn{13}{|l|}{ Booby independence } \\
\hline \multicolumn{13}{|l|}{ Pelican breeding onset } \\
\hline \multicolumn{13}{|l|}{ Pelican independence } \\
\hline \multicolumn{13}{|l|}{ Upwelling strength } \\
\hline \multicolumn{13}{|l|}{ Primary production } \\
\hline Anchovy availability & & & & & & & & & & & & \\
\hline Anchovy abundance & & & & & & & & & & & & \\
\hline \multicolumn{13}{|l|}{ Anchovy condition } \\
\hline Reproduction of anchovy & & & & & & & & & & & & \\
\hline
\end{tabular}

FIG. 4. Schematic representation of the onset (black) and termination (i.e., fledging; gray) of breeding seasons for cormorants, boobies, and pelicans related to seasonal variability in environmental conditions. In the section of seasonal variability in environmental condition, black indicates maximum and gray indicates minimum values; cross bars indicate no data.

breeding season compared to boobies and pelicans. Indeed cormorants appeared to breed most of the year (except during the months of January-March), whereas boobies and pelicans mainly restricted their breeding period to the austral spring. During the austral spring, upwelling strength was intense and associated with cold sea surface temperatures and low surface chlorophyll concentrations. At this time, prey also appeared to be less available (deeper oxycline) and of poorer physiological condition (low body condition factor). Conversely, breeding mainly stopped in summer when upwelling strength was weakest and associated with warmer sea surface temperatures and higher surface chlorophyll concentrations. At this time, prey was more available to seabirds due to a shallower oxycline, with a recovery in physiological condition (body condition of anchovy higher than during months of breeding onset). Thus, our data suggest that environmental factors had a stronger effect on breeding onset in boobies and pelicans than they did in cormorants (Fig. 4). Furthermore, this effect seemed to occur with as much as a 1-month time lag, as evidenced by the time lag between oceanographic and prey condition measures and the observed effects on breeding timing.

\section{Seasonal variability in oceanographic conditions and anchovy availability}

In the NHCS, two factors play a major role in the seasonality of ecosystem productivity: the upwelling strength and the pycnocline depth (Echevin et al. 2008). Although active throughout the year, the upwelling is strongest during the austral winter and weakest during the summer. However, the strongest phase of the upwelling is also the less productive, so that upwelling strength and primary productivity are negatively related in the NHCS (Echevin et al. 2008). This phase opposition, a unique feature of the NHCS in comparison with other EBUEs (Romero et al. 2002, Bograd et al. 2009), is due to light limitation in winter and a shallower pycnocline depth in spring and summer than in winter (Echevin et al. 2008). The seasonal trend in pycnocline depth is also observed in the oxycline depth (Appendix S5: Fig. E1), given the intercorrelation of those two parameters (Bertrand et al. 2014). The oxycline is indeed shallower in summer, constraining the vertical distribution of anchovy to a thin surface layer easily accessible to seabirds. In winter, the oxycline deepens, allowing anchovy to increase their vertical distribution range, thereby reducing their availability to seabirds.

Interestingly, anchovy also varied seasonally in terms of their horizontal distribution. Anchovy biomass close to the coast was higher in summer than in winter (Appendix S6: Fig. F2a), most likely due to the arrival of new recruits (Oliveros-Ramos and Peña 2011), and to the distribution of water masses. Indeed, anchovy horizontal habitat range is intimately linked to highly productive, cold coastal waters (Bertrand et al. 2004, Swartzman et al. 2008), in which geographical distribution depends on upwelling intensity. Accordingly, anchovy habitat range is greater in winter (up to $60 \mathrm{~km}$ from the coast) than in summer (up to $40 \mathrm{~km}$ from the coast) (Swartzman et al. 2008).

\section{Effect of nesting habitat characteristics on breeding onset}

We found no effect of latitude on breeding onset for our three study species, as sometimes documented in seabirds (Wolf et al. 2009). This lack of a relationship could be explained by the relatively weak latitudinal differences in oceanographic conditions 
along the studied region. However, we found a preference for breeding on islands rather than on headlands for all three species, and especially outer islands for pelicans. Until the 1940s, islands were free of terrestrial predators (cats, dogs, foxes), providing safe breeding grounds for seabirds. During the early 1940s, Peruvian authorities began to fence off coastal headlands in order to provide more nesting space for seabirds, thereby enhancing guano production (Vogt 1942). This increase in secured nesting habitats resulted in an increase in the breeding populations of our three study species (Duffy 1983). Nevertheless, our results show that seabirds still preferred to nest on islands rather than headlands, suggesting the latter may be suboptimal breeding habitat. This is indeed likely to be the case, as over the last two decades human population along the Peruvian coast has increased, and seabirds nesting on headlands have become more susceptible to egg poaching and illegal hunting (AGRORURAL, personal communication). In addition, the disturbance of breeding colonies by terrestrial predators may still occur in headlands, since fences are not entirely predator proof.

\section{Seasonal breeding patterns in relation to oceanographic conditions and anchovy availability}

The seasonal breeding pattern related to oceanographic and prey conditions described previously was more evident for pelicans and boobies than for cormorants. During the study period, cormorants had an extended breeding period lasting for more than half of the year. The ability of cormorant to breed almost year-round may be linked to their feeding strategy. Indeed, while hunting, cormorants actively search for prey by pursuit-diving, and may be less sensitive to seasonal variation in prey availability (Sabarros et al. 2012). This hypothesis seems to be confirmed by the observation that, in the NHCS, cormorants may dive as deep as $70 \mathrm{~m}$ while foraging (Zavalaga and Paredes 1999), actively searching for their prey over the entire vertical range of the anchovy habitat (Weimerskirch et al. 2012). In contrast, boobies and pelicans do not actively seek out prey, but forage by plunging (top $10 \mathrm{~m}$ of the water column) or seizing prey items (top $2 \mathrm{~m}$ ) at the surface (Duffy 1980, Weimerskirch et al. 2012).

For boobies and pelicans, breeding was mostly confined to a restricted period of the year. Our data suggest that optimal oceanographic conditions and food availability conditions did not coincide with egg laying or incubation, but rather with chick fledging. Indeed, during egg laying and incubation, the oxycline was one of the deepest in the year, the upwelling current was strong, and anchovies were likely not concentrated near the coast. However, as the season progresses, primary productivity increases, and anchovies likely concentrate near the coast by the time birds are feeding chicks (December). Maxima of primary productivity, abundance, availability, and prey condition may thus be optimal when chicks of boobies and pelicans become independent (January-March).

Therefore, we suggest that boobies and pelicans have adjusted their cycle so that chick fledging coincides with periods of high resource quality and availability. Our findings support the hypothesis of an optimal breeding time rather than an egg-laying constraint, except that in this particular case, optimal food conditions are matched to support chick fledging rather than chick development, as originally proposed by Lack (1968). Optimal resource availability at fledging may maximize juvenile survival by increasing the foraging success of inexperienced young. When compared to adults, foraging success is indeed often lower in juvenile seabirds as they are usually less skillful at capturing prey (Brandt 1984, Daunt et al. 2007). Nonexclusively, optimal prey availability after breeding could also be important for adults during molt (Green et al. 2009). For most bird species, including seabirds, the timing of molt and breeding are separated because those two activities are energetically expensive (Bridge 2006, Green et al. 2009). Unfortunately, we have little information on the duration and timing of molt for the studied species. However, patterns at the family level for cormorants and boobies and at the generic level for pelicans, suggest that the onset of molting flight feathers begins a few weeks after the young reach independence (Schreiber 1980, Bridge 2006).

By contrast, cormorants initiated breeding just after the peak of anchovy abundance in autumn, which may support the idea that those animals might have been at least partially constrained by nutritional requirements for egg laying. This hypothesis is consistent with the fact that cormorants lay the largest clutches of the three species (mean clutch size: 3.1 vs. 2.5 eggs for boobies and pelicans; Nelson 2005). On the other hand, the extended breeding period of cormorants also suggests that individuals may be able to adjust breeding timing to maximize juvenile survival as well, as is the case for boobies and pelicans. More detailed studies at the individual level are necessary to evaluate the constraints faced by cormorants to initiate breeding and to tease apart whether cormorants are able to adjust their breeding cycle to meet an optimal breeding window, all while being somewhat energetically constrained during incubation.

\section{Comparison with seasonal breeding in other eastern boundary upwelling ecosystems}

Seabird seasonal breeding has been documented in other EBUEs and the underlying mechanisms may differ from the ones highlighted in our study. In the Benguela Upwelling System (South Africa), Cape Gannets (Morus capensis) initiate breeding when upwelling strength and primary productivity are maximal. 
At this time, food availability is high due to the presence of dense shoals of sardines and anchovies spawning near the coast (Sabarros et al. 2012). In contrast, at the end of breeding, high mortality is observed in juvenile gannets that migrate from the coast of southwestern Africa, up the western and eastern coasts of Africa, to tropical waters following shoals of sardines (Broekhuysen et al. 1961). In this ecosystem, breeding timing is most likely constrained by food availability at the beginning of the breeding season. In the California Upwelling System, both winter and summer upwellings are important, but in different ways. For instance, Cassin's Auklet (Ptychoramphus aleuticus) fledging success is associated with the summer upwelling mode, suggesting an adaptation of the breeding timing to prey availability (Ainley et al. 1996, Black et al. 2011). However, in the same system, stronger winter upwelling is associated with earlier laying dates for Cassin's Auklets and Common Murres (Uria aalge), suggesting that pre-laying nutritional stress may also be critical to these seabirds (Schroeder et al. 2009, Black et al. 2010, Thompson et al. 2012, García-Reyes et al. 2013). Finally, in the Southern California Bight (a sub-region of the California Current), the reproductive season, location, and breeding effort of Brown Pelicans (Pelecanus occidentalis) appears to be linked to the availability of food resources before the breeding season (winter; Anderson and Gress 1983), according to the egg-laying constraint hypothesis. This is not the case for the Peruvian Pelican.

The specific nature of the environmental cues used by seabirds to initiate breeding events remains to be determined. In the absence of egg-laying constraints, females may use environmental information available early in the season environment to fine-tune egg production annually (Noordwijk et al. 1995). For seabirds of EBUEs, possible environmental cues might include changes in sea surface temperature and/or upwelling intensity related to future prey availability (Frederiksen et al. 2004, Schroeder et al. 2009). In the NHCS, a low-latitude ecosystem, possible environmental cues might also include upwelling activity or ocean surface characteristics, such as water turbulence, which is known to create ephemeral oases concentrating marine life from plankton to birds (Bertrand et al. 2014). According to our data, upwelling occurrence and strength could forecast food availability for at least a month after the onset of breeding. Another, more direct, environmental cue for breeding seabirds could also be the onset of anchovy spawning that mainly occurs during the egg-laying period. The timing of anchovy spawning likely forecast anchovy availability later in the in summer and fall when recruits integrate the stock (Oliveros-Ramos and Peña 2011), at the period when most young seabirds become independent. These hypotheses offer exciting perspectives to test how environmental cues trigger determine seabird breeding onset, and to better understand the consequences of interannual variability in environmental conditions on seabird reproduction.

\section{ACKNOWLEDGMENTS}

We greatly acknowledge AGRORURAL for providing seabird census data. We thank LMI-DISCOH and the ANR project TOPINEME for data and financial support of this work as part of the $\mathrm{PhD}$ thesis of G. Passuni. This work is a contribution to the cooperation agreement between the Instituto del Mar del Peru (IMARPE) and the Institut de Recherche pour le Développement (IRD). This publication was made possible through support provided by the IRDDPF. We thank William Sydeman and an anonymous reviewer who helped improve an earlier version of the manuscript.

\section{Literature Cited}

Ainley, D. G., L. B. Spear, and S. G. Allen. 1996. Variation in the diet of Cassin's Auklet reveals spatial, seasonal, and decadal occurrence patterns of euphausiids off California, USA. Marine Ecology Progress Series 137:1-10.

Anderson, D. W., and F. Gress. 1983. Status of a Northern population of California Brown Pelicans. Condor 85:79-88.

Bertrand, A., M. Segura, M. Gutierrez, and L. Vasquez. 2004. From small-scale habitat loopholes to decadal cycles: a habitat-based hypothesis explaining fluctuation in pelagic fish populations off Peru. Fish and Fisheries 5:296-316.

Bertrand, A., M. Ballón, and A. Chaigneau. 2010. Acoustic observation of living organisms reveals the upper limit of the oxygen minimum zone. PLoS ONE 5(4):e10330.

Bertrand, A., A. Chaigneau, S. Peraltilla, J. Ledesma, M. Graco, F. Monetti, and F. P. Chavez. 2011. Oxygen: a fundamental property regulating pelagic ecosystem structure in the coastal southeastern tropical Pacific. PLoS ONE 6:e29558.

Bertrand, S., R. Joo, C. Arbulu Smet, Y. Tremblay, C. Barbraud, and H. Weimerskirch. 2012. Local depletion by a fishery can affect seabird foraging. Journal of Applied Ecology 49:11681177.

Bertrand, A., D. Grados, F. Colas, S. Bertrand, X. Capet, A. Chaigneau, G. Vargas, A. Mousseigne, and R. Fablet. 2014. Broad impacts of fine-scale dynamics on seascape structure from zooplankton to seabirds. Nature Communications 5:5239.

Black, B. A., I. D. Schroeder, W. J. Sydeman, S. J. Bograd, and P. W. Lawson. 2010. Wintertime ocean conditions synchronize rockfish growth and seabird reproduction in the central California Current ecosystem. Canadian Journal of Fisheries and Aquatic Sciences 67:1149-1158.

Black, B. A., I. D. Schroeder, W. J. Sydeman, S. J. Bograd, B. K. Wells, and F. B. Schwing. 2011. Winter and summer upwelling modes and their biological importance in the California Current ecosystem. Global Change Biology 17:2536-2545.

Bograd, S. J., I. Schroeder, N. Sarkar, Q. Xuemei, W. J. Sydeman, and F. B. Schwing. 2009. Phenology of coastal upwelling in the California Current. Geophysical Research Letters 36:L01602.

Brandt, C. A. 1984. Age and hunting success in the Brown Pelican: influences of skill and patch choice on foraging efficiency. Oecologia 62:132-137.

Bridge, E. S. 2006. Influences of morphology and behavior on wing-molt strategies in seabirds. Marine Ornithology 34:7-19.

Broekhuysen, G., R. Liversidge, and R. Rand. 1961. The South African Gannet Morus capensis. I. Distribution and movements. Ostrich 32:1-19.

Buitrón, B., A. Perea, J. Mori, J. Sánchez, and C. Roque. 2011. Protocolo para estudios sobre el proceso reproductivo de peces pelágicos y demersales. Informe IMARPE 38:373-384. 
Burnham, K., and D. Anderson. 2002. Model selection and multimodel inference, Second edition. Springer, New York, New York, USA.

Chavez, F. P., and M. Messié. 2009. A comparison of Eastern Boundary Upwelling Ecosystems. Progress in Oceanography 83:80-96.

Cushing, D. H. 1990. Plankton production and year-class strength in fish populations: an update of the match/mismatch hypothesis. Advances in Marine Biology 26:249-293.

Daunt, F., V. Afanasyev, A. Adam, J. P. Croxall, and S. Wanless. 2007. From cradle to early grave: juvenile mortality in European Shags Phalacrocorax aristotelis results from inadequate development of foraging proficiency. Biology Letters 3:371374.

Drent, R., and S. Daan. 1980. The prudent parent: energetic adjustments in avian breeding. Ardea 68:225-252.

Duffy, D. C. 1980. Patterns of piracy by Peruvian seabirds: a depth hypothesis. Ibis 122:521-525.

Duffy, D. C. 1983. Competition for nesting space among Peruvian guano birds. Auk 100:680-688.

Duffy, D. C. 1990. Seabirds and the 1982-1984 El Niño Southern Oscillation. Pages 395-415 in P. W. Glynn, editor. Global ecological consequences of the 1982-83 El Nino-Southern Oscillation. Elsevier, Amsterdam, Netherlands.

Duffy, D. C. 1994. The guano islands of Peru: the once and future management of a renewable resource. BirdLife Conservation Series 1:68-76.

Echevin, V., O. Aumont, J. Ledesma, and G. Flores. 2008. The seasonal cycle of surface chlorophyll in the Peruvian upwelling system: a modelling study. Progress in Oceanography 79:167-176.

Foote, K. G., H. P. Knudsen, G. Vestnes, D. N. MacLennan, and E. J. Simmonds. 1987. Calibration of acoustic instruments for fish density estimation: a practical guide. ICES Cooperative Research Report 144:1-57.

Frederiksen, M., M. Harris, F. Daunt, P. Rothery, and S. Wanless. 2004. Scale-dependent climate signals drive breeding phenology of three seabird species. Global Change Biology 10:1214-1221.

Fuenzalida, R., W. Schneider, J. Garcés-Vargas, L. Bravo, and C. Lange. 2009. Vertical and horizontal extension of the oxygen minimum zone in the eastern South Pacific Ocean. Deep Sea Research Part II: Topical Studies in Oceanography 56:992-1003.

García-Reyes, M., W. J. Sydeman, S. A. Thompson, B. A. Black, R. R. Rykaczewski, J. A. Thayer, and S. J. Bograd. 2013. Integrated assessment of wind effects on central California's pelagic ecosystem. Ecosystems 16:722-735.

Green, J. A., I. L. Boyd, A. J. Woakes, N. L. Warren, and P. J. Butler. 2009. Evaluating the prudence of parents: daily energy expenditure throughout the annual cycle of a free-ranging bird, the Macaroni Penguin Eudyptes chrysolophus. Journal of Avian Biology 40:529-538.

Grosbois, V., O. Gimenez, J. M. Gaillard, R. Pradel, C. Barbraud, J. Clobert, A. P. Møller, and H. Weimerskirch. 2008. Assessing the impact of climate variation on survival in vertebrate populations. Biological Reviews of the Cambridge Philosophical Society 83:357-399.

Gutiérrez, M., G. Swartzman, A. Bertrand, and S. Bertrand. 2007. Anchovy (Engraulis ringens) and sardine (Sardinops sagax) spatial dynamics and aggregation patterns in the Humboldt Current ecosystem, Peru, from 1983-2003. Fisheries Oceanography 16:155-168.

Hamer, K. C., E. A. Schreiber, and J. Burger. 2002. Breeding biology, life histories, and life history-environment interactions in seabirds. Pages 218-261 in P. Lutz, editor. Biology of marine birds. CRC Press, Boca Raton, Florida, USA.
Jahncke, J., and L. Paz-Soldan. 1998. La biologia reproductiva de las aves guaneras y sus relaciones con la disponibilidad de anchoveta. Boletin del Instituto del Mar del Peru 17:55-66.

Jahncke, J., D. M. Checkley, and G. Hunt. 2004. Trends in carbon flux to seabirds in the Peruvian upwelling system: effects of wind and fisheries on population regulation. Fisheries Oceanography 13:208-223.

Jaquemet, S., M. Le Corre, and G. D. Quartly. 2007. Ocean control of the breeding regime of the Sooty Tern in the southwest Indian Ocean. Deep Sea Research Part I 54:130-142.

Jeyasingham, W. S., S. A. Taylor, C. B. Zavalaga, A. Simeone, and V. L. Friesen. 2013. Specialization to cold-water upwellings may facilitate gene flow in seabirds: new evidence from the Peruvian Pelican Pelecanus thagus (Pelecaniformes: Pelecanidae). Journal of Avian Biology 44:297-304.

Jordan, R., and H. Fuentes. 1966. Las poblaciones de aves guaneras y su situacion actual. Boletin del Instituto del Mar del Peru 10:1-30.

Lack, D. 1968. Ecological adaptations for breeding in birds. Methuen, London, UK.

Le Corre, M. 2001. Breeding seasons of seabirds at Europa Island (southern Mozambique Channel) in relation to seasonal changes in the marine environment. Journal of Zoology 254:239-249.

MacKenzie, D. I., J. D. Nichols, J. A. Royle, K. H. Pollock, L. L. Bailey, and J. E. Hines. 2005. Occupancy estimation and modeling inferring patterns and dynamics of species occurrence. Elsevier, Amsterdam, Netherlands.

Nelson, B. 2005. Pelicans, cormorants and their relatives Pelecanidae, Sulidae, Phalacrocoracidae, Anhingidae, Fregatidae, Phaethontidae. Pages 1-661 in D. Roberson, editor. Bird families of the world. Oxford University Press, Oxford, UK.

Noordwijk, A., R. H. McCleery, and C. Perrins. 1995. Selection for the timing of Great Tit breeding in relation to caterpillar growth and temperature. Journal of Animal Ecology 64:451458 .

Oliveros-Ramos, R., and C. Peña. 2011. Modeling and analysis of the recruitment of Peruvian anchovy (Engraulis ringens) between 1961 and 2009. Ciencias Marinas 37:659-674.

Perrins, C. 1970. The timing of birds' breeding seasons. Ibis 112:242-255.

Prendergast, B. J. 2005. Internalization of seasonal time. Hormones and Behavior 48:503-511.

Romero, O., B. Boeckel, B. Donner, G. Lavik, G. Fischer, and G. Wefer. 2002. Seasonal productivity dynamics in the pelagic central Benguela System inferred from the flux of carbonate and silicate organisms. Journal of Marine Systems 37:259-278.

Sabarros, P., J. M. Durant, D. Gremillet, R. J. M. Crawford, and N. C. Stenseth. 2012. Differential responses of three sympatric seabirds to spatial-temporal variability in shared resources. Marine Ecology Progress Series 468:291-301.

Schreiber, R. W. 1980. Nesting chronology of the Eastern Brown Pelican. Auk 97:491-508.

Schroeder, I., W. Sydeman, N. Sarkar, S. Thompson, S. Bograd, and F. Schwing. 2009. Winter pre-conditioning of seabird phenology in the California Current. Marine Ecology Progress Series 393:211-223.

Shultz, M., J. Piatt, A. Harding, A. Kettle, and T. Van Pelt. 2009. Timing of breeding and reproductive performance in murres and kittiwakes reflect mismatched seasonal prey dynamics. Marine Ecology Progress Series 393:247-258.

Simmonds, J. E., and D. N. Maclennan. 2005. Fisheries acoustics: theory and practice. Reviews in Fish Biology and Fisheries 17(4):633-634.

Simmonds, J., M. Gutierrez, A. Chipollini, F. Gerlotto, M. Woillez, and A. Bertrand. 2009. Optimizing the design of acoustic 
surveys of Peruvian anchoveta. ICES Journal of Marine Science 66:1341-1348.

Swartzman, G., A. Bertrand, M. Gutiérrez, S. Bertrand, and L. Vasquez. 2008. The relationship of anchovy and sardine to water masses in the Peruvian Humboldt Current System from 1983 to 2005. Progress in Oceanography 79:228-237.

Sydeman, W. J., M. García-Reyes, D. Schoeman, R. R. Rykaczewski, S. A. Thompson, B. Black, and S. J. Bograd. 2014. Climate change and wind intensification in coastal upwelling ecosystems. Science 345:77-80.

Thompson, S. A., W. J. Sydeman, J. A. Santora, B. A. Black, R. M. Suryan, J. Calambokidis, W. T. Peterson, and S. J. Bograd. 2012. Linking predators to seasonality of upwelling: using food web indicators and path analysis to infer trophic connections. Progress in Oceanography 101:106-120.

Vogt, W. 1942. Informe sobre las aves guaneras. Boletin de la Compañia Administradora de Guano, XVIII: 1 XVIII:1-132.

Weimerskirch, H., S. Bertrand, J. Silva, C. Bost, and S. Peraltilla. 2012. Foraging in Guanay Cormorant and Peruvian
Booby, the major guano-producing seabirds in the Humboldt Current System. Marine Ecology Progress Series 458:231245.

Wingfield, J. C., and G. J. Kenagy. 1991. Natural regulation of reproductive cycles. Pages 18-241 in P. K. T. Pang, and M. P. Schreibman, editors. Vertebrate endocrinology: fundamentals and biomedical implications. Academic Press, San Diego, California, USA.

Wolf, S. G., W. J. Sydeman, J. M. Hipfner, C. L. Abraham, B. R. Tershy, and D. A. Croll. 2009. Range-wide reproductive consequences of ocean climate variability for the seabird Cassin's Auklet. Ecology 90:742-753.

Zavalaga, C. B., and R. Paredes. 1999. Foraging behaviour and diet of the Guanay Cormorant. South African Journal of Marine Science 21:251-258.

Zavalaga, C. B., G. Dell'Omo, P. Becciu, and K. Yoda. 2011. Patterns of GPS tracks suggest nocturnal foraging by incubating Peruvian Pelicans (Pelecanus thagus). PLoS ONE 6:e19966.

\section{SUPPORTING INFORMATION}

Additional supporting information may be found in the online version of this article at http://onlinelibrary.wiley.com/ doi/10.1890/14-1134.1/suppinfo 